Reinserting the professional into the study of

globalizing professional service firms: the case of

law

James R Faulconbridge*, Department of Geography, Lancaster University, Lancaster, LA1 4YW j.faulconbridge@lancaster.ac.uk

Daniel Muzio, Lancaster University Management School, Lancaster University, Lancaster, LA1 4YW

d.muzio@lancaster.ac.uk 


\title{
Reinserting the professional into the study of
}

\section{globalizing professional service firms: the case of}

\section{law}

\begin{abstract}
In discussions of the globalization of professional service firms there is an increasing recognition that understanding the 'social construction' of organizational architectures is essential. In this paper we argue, using the management of transnational law firms as an example, that to effectively understand these social constructions we must reincorporate an understanding of the principles of professionalism into discussions. We highlight the importance of occupational autonomy to professionals and how this is likely to influence the strategies used by global professional service firms. We also point to what we term the 'varieties of professionalism' and the spatially variable professional projects that underlie the values and identities of lawyers. This reveals the way rational and efficient forms of organizing have to be adapted as a result of professional values and the diverse ideals and beliefs of lawyers in different international jurisdictions.
\end{abstract}

Keywords: Professional service firms; Professionalism; Varieties of Professionalism; Globalization; Legal Practice 


\section{Reinserting the professional into the study of globalizing professional service firms: the case of law}

\section{Introduction}

Globalization, and the emergence of transnational corporations (TNCs), has posed a range of challenges in terms of the organizational architectures of firms. This trend is clearly illustrated by the globalization of service firms over the last two decades (Aharoni 1993; Daniels et al. 1988; Enderwick 1989). Occupations ranging from retailers (Wrigley et al. 2005) to temporary staffing agencies (Ward 2005) have set about establishing overseas subsidiaries but perhaps of most significance has been the globalization of a number of professional industries, exemplified most prolifically by accountancy firms and most recently by the newly emerging cadre of transnational law firms. Intricately wrapped up in the globalization process as 'lubricators' of global economic activities (Dicken 2003), these global professional service firms (PSFs) are now involved in all of the major cross-border corporate deals and operations that dominate discussions in publications such as The Financial Times.

In the earliest stages the emergence of a multinational configuration was noted in transnational service firms (Daniels 1993). The new outposts of predominantly US and UK originating companies were controlled by their respective headquarters and leveraged competitive advantages developed in the home country of the firm. Consequently, overseas branches primarily catered to the needs of existing clients as they themselves globalized. In 
contrast, it is now increasingly recognised that new forms of competitive advantage have to be generated through globalization. Bartlett and Ghoshal (1998) describe how transnational forms of control are based upon intersubsidiary and subsidiary-headquarters consultation and collaboration that informs innovation, decision-making and strategy. As has been described in relation to law firms, this can take the form of inter-office collaboration, knowledge sharing and learning (Faulconbridge in press) as well as crossreferrals of work and the inter-office mobility of employees (Beaverstock 2004). Implicit yet not always central in discussions of such contemporary organizational architectures is acknowledgement of their social foundations. For example, Jones (2002) draws our attention to the fact that diffuse, transnational, modes of control and power mean "global corporate strategy is a negotiated and fluid phenomenon that emerges...'from a continual process of discussion" (Jones 2002: 346). Such negotiations are inevitably politically charged. Bartlett and Ghoshal (1998: 204 original emphasis) point out that those chief executives that are successful at managing contemporary TNCs are those "concerned with the perceptions and behaviours of individual managers within the organization, trying to ensure that they share an understanding of the company's purpose and values, an identification with boarder goals, and commitment to the overall corporate agenda". Hence, for Morgan (2001) managing a transnational firm is a delicate process that involves negotiating the construction of social, relational spaces and communities that facilitate managerial coordination and control. 
In this paper we use the management of transnational law firms to point to what we see as a surprising void both in these 'socially sensitive' approaches to the analysis of global PSFs (e.g. Morgan 2001; Jones 2002) and in more normative theories of recent organizational change (e.g. Cooper et al. 1996). These literatures acknowledge the difficulties of implementing the hierarchical, efficiency-led management systems used in many TNCs and the lack of HQ-led coordination in PSFs. However, they often struggle to account for this peculiarity, in part because they try to explain the globalization and management of PSFs using theory developed through the study of manufacturing organizations and without consideration of the peculiarities of professional behaviours and norms. Therefore, here we use empirical data collected through interviews with lawyers working for transnational law firms to begin to explain how the archetypal transnational organizational form is compromised in PSFs by the agency of reflexive and spatially heterogeneous professionals. In particular we show that the peculiarities of professionalism as an occupational principle (Freidson 2001; Mintzberg 1983; Raelin 1991) mean lawyers, as professionals, demand autonomy in their work and input into the strategic direction of the firm. This prevents most forms of hierarchical, top-down management, means global coordination of the firm becomes difficult and makes negotiations cumbersome as all partners seek to contribute to decision-making. In addition we show how spatially variegated, institutionalised professional projects create nationally contingent work behaviours, beliefs and ideals. The latter is what we term the 'varieties of professionalism' (c.f. Hall and Soskice 2001; Whitley 1998) and what others have called the national 
system of the professions (Burrage and Torstendahl 1990). Combined this means that not only are negotiations relating to the organization and coordination of the firm awkward to manage but also that agreement about management strategy is hard to reach as the principles and work-related beliefs and ideals of lawyers vary between offices. It is our contention that understanding these characteristics and effects of professionalism might provide more intricate and insightful analyses of the globalization of PSFs and explain the unique organizational forms used by globalizing PSFs, their spatial variability and consequently their often suboptimal, irrational and idiosyncratic nature.

The rest of the paper, therefore, proceeds over five further sections. The next section explores the different ways the globalization of PSFs has been theorised and documented and, in particular, why 'socially sensitive' analyses have been called for. The following section then suggests such 'socially sensitive' analyses might benefit from the incorporation of understandings of professionalism and its affects on the organizational structures of global PSFs. Here the idea of the 'national varieties of professionalism' is fleshed out. The following two sections then explore original empirical material that highlights the peculiar management strategies used in global legal PSFs (consultation and consensus) and the way professionalism and its spatial varieties create fragmented organizational forms that are anomalous compared to those used in many manufacturing firms. The final section offers some conclusions and calls for further consideration of the nature and effects of professionalism in a range 
of industries and the implications of this for the all-encompassing use of the term PSF.

\section{Globalization and the changing PSF}

There is much debate about the exact meaning of the term PSF (e.g. Alvesson 2004; Lowendahl 2005), something we do not want to become overly embroiled in here. Instead, for the purposes of this paper we use PSF to refer to firms employing professionals, as defined in the strictest sociological sense. This means industries where entry and practice is closely regulated as part of a professional project, something that creates shared identities and values for all in the profession (Freidson 2001; Burrage and Torstendahl 1990). This usually refers principally to accountants, architects, lawyers and medical doctors (Broadbent et al. 1997) and not some of the other industries (e.g. advertising, management consultancy) classed as PSFs because of the bespoke and knowledge rich characteristics of the services they provide. As we show below, deliberately using such a strict definition, something others including ourselves have not done in the past, is significant and has important implications for the way we use the term PSF. However, this also means that we should be cautious not to over generalise from our findings. Our data pertains to globalizing law firms. This can begin to inform discussions of other professional industries because of the professional principles of a formalised education system, market closure and regulation that are shared with accountancy, architecture and medicine. Many of the organizational challenges faced by law firms have been or are currently being faced by these professional 
occupations. However, law is also potentially different in many ways to these other professions. We, therefore, use the case of law to support our call for wider studies of all professions as a pressing research need and return to definitional issues at the end of the paper.

Away from such definitional concerns, interest has been shown across the social sciences in, broadly defined, the globalization of PSFs (Aharoni 1993; Daniels 1993; Cooper et al. 1996; Brock et al. 1999; Lowendahl 2005). Interest in law firms is one of the most recent preoccupations because of the relatively late globalization of these firms. Whilst the first transnational law firm, Baker and McKenzie, began opening overseas offices in 1955 it wasn't until the late 1970's that others began to develop a coordinated globalization strategy. Thus, law firms have a significantly less pronounced global footprint than other professions such as accountancy (Beaverstock et al. 1999). The globalization strategy of these globalizing law firms (table 1) is to target key financial centres and open offices where existing clients have business interests and new clients can be recruited. They seek "to provide consistently high quality advice that combines technical expertise, and an understanding of the commercial environment in which our clients operate". Thus, their strategy is to "offer indepth local knowledge and a uniquely global perspective" (http://www.cliffordchance.com/about us/about the firm/ [accessed 12/12/2006). In effect, these law firms stitch-together global deals by using transnational legal arrangements.

[Insert table 1 somewhere here] 


\section{Rationalising globalization}

This globalization process can, in many ways, be explained using existing scholarship examining the globalization of PSFs. Here, the more intricate analyses have used Dunning and Norman's (1987) eclectic paradigm to theorise the logic behind globalization (Bagschi-Sen and Sen 1997; Beaverstock 2004). This reveals how globalization can be explained with reference to three forms of advantage gained through foreign direct investment (FDI).

Ownership advantages - when the unique assets of the firm, whether they are the knowledge of employees or the reputation accrued through years of high quality service provision, are leveraged overseas.

Location advantages - the payback gained from presence in a particular place or market. For instance, presence in a particular strategic location can generate significant benefits by supporting firm-wide innovation through the knowledge assets generated by key overseas offices (Faulconbridge 2006; Lowendahl 2005).

Internalisation advantages - the reimbursement gained when FDI rather than licensing or franchising is used to deliver a service is, in certain circumstances, of paramount importance.

Thus, in the contemporary PSF the aim is to create competitive advantage by organizing in a way that allows the assets held by one branch to be leveraged by other subsidiaries. This requires, however, effective coordination strategies. 


\section{Managerial practices in global PSFs}

One consequence of the globalization of PSFs is said to be the need to reinvent the organizational forms used to manage office networks. In particular, the abandoning of traditional organizational configurations of professionalism and partnership (P2) has been noted (Greenwood et al. 1990). In the P2 form control and coordination are characterised by intimacy, informality, negotiation, compromise and collegiality. It has been suggested that firms are restructuring themselves around a new archetype, the Managerial Professional Business (MPB), where there is a 'significant refocusing upon the business and management values of efficiency, costeffectiveness, central strategic control, and internally differentiated structures' (Brock et al. 1999: 219). In other words, new opportunities connected with globalization, de-regulation and technological innovation are said to have triggered a managerial revolution and the emergence of new optimal forms of governance in firms that allow the centralised coordination of worldwide activities.

Global PSFs should therefore be expected, according to archetype theorists (Brock et al. 1999; Cooper et al. 1996), to 'introduce, rationalize and bureaucratize the process of strategic planning' in order to create new competitive advantage across global office networks (Hinings et al. 1999, 141). This is expected to include the emergence of a dedicated managerial hierarchy, equipped with powers of imperative coordination, which can help minimise the disruptions caused by political negotiations between actors in different parts of the firm. Hybrid figures such as lead partners and managing partners are appointed and equipped with increasing executive 
powers. The former are given a 'strong responsibility for directing partners in other offices, setting fee levels and hours to be worked" whilst the latter "have responsibility for the business plans of their units and for the evaluation of partners and all staff" (Hinings et al. 1999: 142). Such descriptions suggest a clear departure from the democratic, participatory and equalitarian traditions of the P2 form and recommend that functions such as billing, customer service, training, recruitment and quality assessment are extracted from the idiosyncratic and ad hoc approaches of individual professionals and administered according to official companywide procedures and regulations.

There is little doubt that important changes have been taking place in the way law firms are managed as they have globalized. As Hanlon and Shapland (1999) describe, large law firms in particular have had to be reorganised to fulfil the requirements of evermore demanding corporate clients. In this context, the work of lawyers is being reconfigured by growing commercial pressures as well as by the realities of operating in increasingly large and complex organizations that can employ several thousand professionals. Our interpretation of this significant process departs somewhat however from the account offered by archetype theorists. In particular, we are sceptical about the extent to which such a wholesale, uniform and uncontested 'managerial' revolution has occurred and argue that whilst work on archetype reconfigurations captures some important empirical trends, it is somewhat under-socialised, especially when compared to the body of literature reviewed below. As a result it fails to fully recognise the role played by professional values, behaviours and identities in the 
organization of PSFs. Indeed, Gray (1999) suggests that any change is likely to be restricted by the reflexivity of professionals in law firms and their resistance to the outright abandonment of traditional professional values. Meanwhile Flood (1999) argues that spatial variability (in his case between English and US lawyers) means that isomorphism and the adoption of homogeneous organizational forms and practices across space are unlikely.

We, therefore, attempt to understand the way the globalization of legal and other PSFs has been influenced by reflexive professional agents. When Morgan (2001:119) suggested "there is very little recognition that firms are social spaces with actors and rules that are socially embedded" he pointed to an increasingly troubling lacuna in research on global firms. Too often firms are positioned as 'black boxes', devoid of human subjectivities, agency and relationships (Taylor and Asheim 2001). Much corrective work has begun to rectify this issue in recent years (e.g. Beaverstock 2004; Empson and Chapman 2006; Jones 2002) but often the insights gained do not percolate into wider theorising relating to the management and organization of contemporary global PSFs. We, therefore, focus in detail upon how an appreciation of the oddities of professionals as social actors, their professionalism and professional practice can help us understand the organizational forms adopted by PSFs.

\section{Bringing the professional back into PSFs}

A useful starting point in the search for ways to fertilize recent studies of PSFs with understandings of professionalism is through the insights provided by work on the sociology of the professions. The contribution of 
Terry Johnson (1972) represents a key moment in the study professionalism. His realization that professions are not always specific occupations per se but that they can also be groups adopting a particular method of organizing and controlling work helped free the sociology of the professions from its earlier taxonomic concerns. Professionalism is, thus, recast as a particular work organization method where the occupation itself, "rather than consumers in an open market (entrepreneurship) or functionaries of a centrally planned and administered firm or state (managerialism)" (Freidson 1994: 32), retain control over work, including "the social and economic methods of organising and performing this work" (Freidson 1970: 185-86). This autonomous form of working contrasts with alternative occupational principles, such as entrepreneurship and managerialism, where work is organized according to either contractual relationships in (relatively) open markets or through a rational-legal apparatus of formal regulations implemented through managerial hierarchies.

This distinction between different occupational principles provides us with an important reference point for understanding recent development in PSFs. Professional workers are not only bound by the rules of their employing organization but also by the standards, principles and objectives of their occupation, something which they internalize following a long period of formal training and informal socialization (Montagna 1968). The most important point here is that professional values are not always reconcilable with organizational employment. Indeed, there is extensive research documenting the frictions and conflicts faced by professionals in 
bureaucratic settings. Work by Montagna (1968), Johnson (1972) Mintzberg (1983) and Raelin (1991), consistently suggests that professionals tend to resent supervisory arrangements and regard managerial decisions as 'arbitrary and inconsistent'. Consequently there is a fundamental tension as managers expect professionals to follow organisational procedures and goals, just like any other employee, whilst professionals often struggle to reconcile their employment duties with the occupational principles and methods of their profession (Raelin 1991: 2). Indeed, more recently, Covaleski et al. (1998) suggest that transnational accountancy firms attempt to override these professional norms using a socialization mechanism whereby senior partners champion the benefits of managerial coordination and control of work. However, as they note, this is often resisted, both by the socializers and socialized, because of the persistence of professional ideals.

In addition, there is an extra lawyer of complexity associated with professionalism. Larson's concept of the professional project is particularly useful in understanding the foundations of important work-related norms, values and identities (1977). This, then, is the strictest sociological definition of professionalism and identifies the way professionalism can act as a socioeconomic advancement strategy. Two features of professionalism are important here (Abel 1988):

Control over the production of producers (occupational closure). This represents an ensemble of technical, cultural and social requirements that limit access to occupational opportunities (and the various associated rewards) to a restricted circle of eligibles. Most commonly this exists in the 
form of the registration requirements necessary to practice as a lawyer, architect or other formal professional. Registration is only granted to those meeting the clearly defined conditions of entry to the profession. In particular such closure allows professions to control the supply side of their market (Abel 1988) with the benefits being considerable as professionals can maximize the financial (and social status) rewards associated with their work whilst enjoying the possibility of reconciling supply and demand trends in their own markets.

Control over production by producers. The professional project is not only concerned with "who produces the services but also [with] how they are produced, distributed and consumed" (Abel 1988: 176). This brings us back to the occupational definitions described above as existing regulations can help to isolate professionals from managerial coordination and rationalization.

The current organization of the legal profession (and accountancy and architecture) is, in Larson's terms (1977), the outcome of such a sustained occupational project. This is grounded and facilitated by a dynamic web of relationships between a number of distinct actors (Burrage et al. 1990; Nelson and Trubek 1992). These include:

- The state that can recognise monopolies, legitimize restrictive practices and, particularly in the common law world (i.e. England and the USA), grant an autonomous regulatory capacity.

- The practicing professionals who through their actions and collective behaviours are said to sustain a common identity or culture. Together, as described below, the interactions between professionals 
and the other actors listed here lead to agreement on the technicalities and modes of professional practice followed by all in the profession.

- Educational institutions reinforce the ideals of regulators but also the practices of professionals by socializing a new generation of practitioners as they undergo compulsory regulated training. They also support evolutions in practice through the development of coherent body of knowledge and provide the formal credentials that can support effective closure regimes.

- Clients define and legitimize professional practice through their demands and expectations.

This is important in our argument as the interactions between these actors create regulated and institutionalised norms, values and ideals relating to professional work that are shared by those in closed, regulated and defined professional arenas. Moreover, these norms vary over time and space according to the shifting roles, interests, priorities and resource capabilities of the actors. This has important consequences for the characteristics of any one national professional project (Burrage et al. 1990; Larson 1977).

\section{National varieties of professionalism?}

The embeddedness of the global organizational networks of PSFs both in home and host countries creates added layers of complexity in the management of firms. As the main arguments in the varieties of capitalism literatures highlight, approaches to the organization of firms vary between countries because of nationally distinctive institutional settings. Hall and 
Soskice (2001: 13) argue that "the institutions of a nation's political economy are inextricably bound up with its history in two respects. On the one hand, they are created by actions, statutory or otherwise. On the other, repeated historical experience builds up a set of common expectations that allows the actors to coordinate effectively with each other". In professional contexts, expectations and institutionalised norms are determined by the nationally specific influences of the various actors involved in their professional project and the ways these socializing influences affect the early years of training and practice of professionals. This is, then, what others have called the national system of the professions (Burrage and Torstendahl 1990; Lane et al. 2002) and we term the 'varieties of professionalism'. Nelson and Trubek (1992: 179) describe its effects on professionalism in law firms in the following way:

"lawyer professionalism is not a fixed, unitary set of values, but instead consists of multiple visions of what constitutes proper behaviour by lawyers. Conceptions of lawyer professionalism reflect 'the arenas' in which they are produced, that is, the particular institutional settings in which groups construct, explicitly or implicitly, models of the law and lawyering".

Law provides, then, an ideal case study to see how the influences of national professional projects influence the organization of globalizing PSFs. Despite moves towards transnational jurisdictions and institutions (Sklair 2001; Trubek et al. 1994), the legal profession is closely connected to the political and juridical system of its country of origin. After all, lawyers in their role as mediators and adjudicators of entitlements and obligations, make a fundamental contribution to those 'governmentality' networks that support 
independent nation-states and their capacity to govern. In other words, of the four agents previously identified, the state, which is arguably the least transnational in their orientation, exercises a particularly strong influence on the development of the legal profession, its work and organization. Inevitably these strong local connections somewhat reduce the extent to which legal knowledge and practices can be reproduced across jurisdictions whilst the differences between legal systems and cultures multiplies the scope for tensions, incompatibilities and misunderstandings within globalizing law firms. So, for example, Morgan and Quack (2005) note how such influences mean German lawyers have traditionally been less entrepreneurial and business orientated than English or American lawyers. Space prohibits us providing further detailed examination of these variations (but see also Flood 1995; MacDonald 1995). The important point here is that it is necessary to develop analyses of the way professionalism as an occupational principle and as a professional project influences the behaviour of all professionals working for globalizing PSFs and, related to this, the spatially fragmented nature of professional practice, systems and ideals. This will make it is possible to better understand the forces constraining and determining the organizational forms used by globalizing PSFs. Below, we examine empirical material to make this case for law firms before considering the significance of these findings to other professional industries such as accounting. 


\section{Professionals and their influence on organizational forms in law firms}

The rest of the paper is based on a series of 25 interviews with partners in the London and New York offices of fifteen of the top twenty transnational law firms by number of offices. Individuals held a range of roles which are identified in the quotes used and, significantly, all had experience of various aspects of the 'management' of global legal PSFs. London and New York were chosen as venues for the interviews for two reasons. First, the major globalizing law firms (table 1) emerged from these two cities and partners in these offices often have extensive experience of the challenges of setting up overseas offices/practice groups. Talking to these individuals allowed the complexity of opening overseas offices that employ locally qualified personnel to be uncovered. Second, it allowed exploration of the challenges US and UK firms have faced when opening offices in one-another's backyards. American and English business systems are often lumped together as one category - Anglo-American - because of the points of convergence that exist. However, this is especially misleading in relation to professional industries where as many differences as similarities can be identified (MacDonald, 1995). Whilst the well-known and less subtle differences between UK and German systems have been extensively explored (e.g. Lane et al. 2002; Morgan and Quack 2005), variations within Anglo-American professional systems have received limited attention. We begin to rectify this issue here.

All interviewees were questioned about (a) the way the global legal PSF they worked for was organized to create effective integration and 
coordination; (b) the distinctiveness of the approaches used and the reasons for this; and (c) the advantages/disadvantages of the forms of organizing used. Interviews lasted 50 minutes on average with all but two recorded and fully transcribed. The themes outlined below emerged as key issues in all of the interviews completed.

\section{Professional autonomy and transnational negotiations}

Interviews suggested that lawyers entered the profession with, and over time became even more fervently wed to the belief that autonomy over both ends (the type of work completed) and means (how work is completed) is necessary in the type of innovative, bespoke legal practice global law firms specialize in. Consequently, it was suggested that management styles and systems must not impede the ability of individual lawyers, and partners in particular, to behave and work independently as 'responsible' professionals. As two lawyers described it:

"So in terms of initiatives to build a practice and build workflow, yes I do have a fair degree of autonomy...Autonomy is extremely important to partners and there has to be a sense in which within the confines of a strategy of the office, practice group or firm, there must be a degree of autonomy where each partner acts..." (5, partner, US law firm in London).

"I don't like being managed and want to have autonomy [but] It's important to be part of a firm and share resources because it allows you to do the most interesting work that otherwise you wouldn't be able to manage" (12, Partner, US law firm, London). 
This suggests, then, that the ideals of managerialism described in archetype theory are somewhat overplayed. Instead, professional values and logics remain in law firms. This, of course, does not mean global PSFs can operate without any form of management. Rather, as the quotes suggest, managerial approaches need to be colonized and adapted so as to allow coordination but also maintain professional ideals. Indeed, different firms have adopted managerial approaches to varying degrees with some placing greater degrees of imperative coordination and control in the hands of senior/managing partners than others. This is the dilemma faced by those running global legal PSFs. Heavy-handed, hierarchical management that enforces policies, procedures and narrow strategy is likely to cause dissent and ultimately the departure of lawyers. As one interviewee said, "my preference as a manager is that people consult me in advance so I don't have to jump and try to implement something. It's awkward, it undercuts the other people, it doesn't make the feel very good if you do that" (8, head of practice group, London). However, too greater degrees of laissez-faire control can be equally destructive. Consequently, negotiated forms of what might be called organizational professionalism are needed. This requires a unique approach whereby an inclusive form of consultation is used in the 'management' process that recognizes the value of professional autonomy but also the constraints that large-scale organizing brings. Table 2 provides details of areas interviewees highlighted as being subject to such forms of professional-sensitive 'managerial' coordination.

[Insert table 2 here] 
Despite the introduction of such degrees of managerial coordination in PSFs, the approach to developing and implementing organizational strategy continues to be unlike that found in most TNCs and certainly can not be understood in strictly functional or efficiency-optimization terms (Ackroyd 2002). In hierarchical organizations, as most TNCs are, the chief executive surrounded by an executive board of directors makes strategy decisions whilst managers at the branch level see to their implementation (Empson and Chapman 2006). In contrast in law firms all partners (and partners represent at least one eighth and up to half the workforce) are given the opportunity to contribute to strategic planning. This is, in part, a function of the partnership system. In effect, every partner is a co-owner of the firm and has an equal right to influence the way the firm operates. Indeed, the allpartner vote remains the ultimate sanction for changes to the organization of the firm. Consequently, the day-to-day running of the largest firms is delegated to committees, typically at the practice group level. Through these committees all partners are consulted about plans and strategy for the practice group they are part of. As one lawyer describes the management process:

"you cannot manage a law firm in the same way as you can in a corporation where there's a power structure and someone orders you to do something, and this is the reporting line, it just doesn't work...What you do find at all levels within these structures, at practice group level or geography, is a process of ideas bubbling up, consultation coming down, well before you ever get to the decision level...And you have a lot of 'low level' one on one consultation, not necessarily very formal consultation, where you're trying to 
identify and build a consensus before you ever put anything to a formal decision" (22, managing partner, New York).

Those on committees have to be voted into the position they hold and can equally have their limited authority removed by a vote from fellow partners. In effect, they represent rather than manage their peers when heading or chairing one of these committees.

Understanding these impacts of professionalism on PSFs is made all the more significant by the further complicating affects of the 'varieties of professionalism'. Together the focus on partner autonomy in firms and cultural heterogeneity mean orthodox forms of globally aligned organization become difficult. Instead reconstituted architectures are needed so as to be responsive to the interests, values and aspirations of the powerful professionals that ultimately generate profit for the firm. However, this means that gelling the firm together and aligning the priorities of all of the strategic workers can become difficult.

\section{'Varieties of professionalism' and complex organizational forms in global legal PSFs}

For globalizing legal PSFs the challenge of managing professionals is exaggerated by the affects of the geographically distributed and embedded office networks that reach across Europe, North American and South East Asia. The type of negotiation and consensus building alluded to earlier has to be sensitive to the norms, ideals and beliefs of professionals emerging from different national systems or what, as suggested previously, might be 
termed the 'national varieties of professionalism'. This dilemma is not particularly new and has been faced by all globalizing PSFs. Indeed, when Baker and McKenzie, the original global law firm, opened its first overseas office in Caracas in 1955 and subsequently other offices in Europe it was recognized that the key challenge was the fact that

"The firm had no blueprint to show it how to patch together a mélange of partners from every major culture, religion, race, and language group on earth...it had no model for whether to give local offices autonomy or weld them together in tight hierarchical structure. Compounding the problem of facing totally new issues, the personalities or the early partners sometimes created stumbling blocks. Many were highly individualistic and entrepreneurial men who rankled at any attempt to control the way they practiced law" (Bauman 1999: xi-xii).

It could be argued that little progress has been made in the past fifty years to rectify this problem. As one lawyer put it:

“it happens all the time, you comment 'that's very German' or 'that's very American' or 'that's very British'. You do tend to recognize and see and comment upon it, but also understand and accept, the cultural differences...And you can come to decisions and create consensus, recognising that people are coming from different cultures and creating something that works across the cultures" (2, managing partner, UK law firm, London).

Nearly all law firms have chosen to approach globalization through the creation of global partnerships whereby all partners, wherever they are located, abide by the same partner constitution and have an equal input into 
the strategy of the firm. Perhaps one of the best examples of the challenge this can create can create can be found in the recently demised Coudert Brothers partnership. This firm, identified by Beaverstock et al. (1999) as a leading globalizer, collapsed in 2005 after an exodus of partners from offices throughout the world. Whilst there are multiple stories to be told in relation to the firm's demise, a significant element in the process was the inability of senior and managing partners to implement an organizational structure that recognised the need for partner autonomy and sensitivity to cultural difference yet also the need for a strong-centre that ties the firm together (New York Law Journal 2005).

At one level the difficulties of this have been documented in relation to the challenges of managing different conceptions of lawyering in common and civil law traditions (Morgan and Quack 2005). In addition, more subtly and closer to the focus of this paper, organizational and working arrangements in UK and US originating global law firms have also be shown to be distinct, creating challenges for firms when opening offices overseas and implementing 'home' country influenced strategies (see table 3).

[Insert table 3 here]

We can characterize UK lawyers, then, as being more collegial in their approach to management, practice and organization. The importance of seniority in remuneration systems, as well as the sharing of responsibility with regards to key activities such as training and decision-making, provides evidence of such a collectivist approach. This is in contrast with the more 
individualist style that typifies US-based firms. Similarly, UK solicitors seem to prefer more informal arrangements and methods with less reliance on formal targets, procedures and mechanisms than their American counterparts. The reasons for such differences are complex but we can begin to explain them by considering the differences in the legal professional projects in each country. For example, the extent to which large-scale, commercially orientated legal practice was permitted in England and the USA varied significantly until relatively recently. As noted earlier, US lawyers have had the freedom to develop commercial, megalaw, practices for many years (since at least the late 1800s) ${ }^{1}$. In contrast, in England the emergence of large, commercial, law firms is a recent phenomenon. Regulation prohibited law firms from having more than 20 partners until 1967 and even then large firms failed to emerge until the mid 1980's, in particular being spurred by 'big bang' in London (Flood 1995). Consequently the norms of professionals in law firms, and the values created and reinforced by universities differ because of divergent expectations about the characteristics of professional work. Similarly clients have different expectations of their lawyers.

These norms translate themselves into a heterogeneous set of practical arrangements that can cause all kinds of tensions when bought together in one firm. As the lawyer quoted above also went on to note, "Our office in Bangkok can't expect us to run it as a Thai law firm. Our office in Dubai can't expect us to regard the Middle East as the centre of our universe because its only two percent of our business...And the UK is in no way the major jurisdiction now, forty percent is UK, twenty percent is US, 
thirty percent is in Europe, so it's really quite a diverse mix". This complexity is a major challenge. It is recognized that having 'locally embedded' offices is important but this cannot lead to locally fragmented islands. This would be untenable in organizations that aim to provide globally aligned and integrated services. Consequently somewhat idiosyncratic organizational forms are needed.

\section{Organizing globally around multiple professional cultures}

As a result of the issues described above, the organizational forms used by global legal PSFs exhibit unique spatial variegation and reflexivity towards the influence of the 'local' cultures they are embedded within. As one interviewee suggested:

"Here you have one of the fundamental management dichotomies in managing large law firms...Generally the practice group is given a high degree of autonomy as to how it manages its practice. So there'll be steers from the global practice head that filter down but how we execute the game plan, who we think our targets are, how we implement them is totally down to us [locally]...It is different from how you manage from a business services point of view where it is much more centralised policy, much more output to the region saying this is what you need to do. When it comes to partnership affairs, every member has an input with high involvement. So the centre has to reach out to all the partners in all the offices to communicate things, so you get a persuasive mode (24, partner, UK law firm in New York). 
This highlights, then, how in global legal PSFs a limited array of top-down, hierarchically controlled policies exist alongside numerous spatially variegated, locally peculiar and 'embedded' approaches that professionals control and dictate. Table 3 gives examples of how key operational, strategic and financial issues (Cooper et al. 1996) are dealt with in the legal PSFs studied using such an approach.

[Insert table 3 here]

Designing effective remuneration models for use in transnational PSFs is probably one of the best-known challenges associated with the varieties of professionalism (Flood 1995). The legal press have also extensively documented the differences that exist, in particular between the models used in US and UK law firms (The Lawyer 1999; 2004; New York Law Journal 2005). In the UK remuneration is normally determined using the lockstep system. This privileges years of service as the major variable in remuneration level. Its underlying ethos is one of teamwork and the model uses the ideal that seniority conflates with ability and contribution to the success of the firm. In contrast, in the USA the 'eat what you kill' model tends to dominate ${ }^{2}$. Here the major variable is billable hours charged to clients (i.e. profits made) and there is no relation to years of service. Lawyers 'compete' and are self-reliant in the sense that their salary is a direct reflection of their financial success in the past twelve months. These approaches reflect the differing and ingrained professional logics of lawyers in the two jurisdictions (table 3) and can even be traced-back to the 
socializing effect of law school where, in the USA, students are ranked hierarchically according to performance whereas, in the UK this is not the case. Consequently, when, for example, the lockstep is implemented in New York (or vice-a-versa and the 'eat what you kill' model is used in London) this causes significant tensions. As one interviewee noted:

"One of the problems many firms are facing is that if you're in a lockstep you don't know anything else. And you jealously protect the system because its part of your culture. And you are suspicious about systems that try to differentiate because it's counter cultural. In a performance related culture, the problem is it tends to promote a star culture. And it tends to incentivize partners to become starts. Which is not necessarily a bad thing, but it tends to be at the expense of collegiate and cooperative behaviour. So there is a different in ideals between the two, and it can be very interesting" (2, managing partner, UK law firm, London).

Being 'interesting' has meant, for many English firms merging with US firms and implementing lockstep remuneration, the loss of many of the most skilled and respected lawyers in the US office. These individuals normally earn most in an 'eat what you kill' system and forcing them to accept lockstep normally causes so much ill feeling that they leave the firm and take their intellectual capital and rainmaking (profit generating) abilities with them. It has, therefore, been noted by the legal press (The Lawyer 2004) that many firms have reverted to a type of reconfigured 'hybrid' model, as described in table 3 . This both maintains global coordination and alignment of remuneration but also allows local embeddedness and sensitivity to professional peculiarities. So, for example, a number of English firms now 
use a modified lockstep that maintains years service as the primary variable in remuneration but also adds-in performance measures which can provide 'super points' that boost a partner's salary. These super points are used to reflect high levels of fee earning and are used most extensively in 'eat what you kill' jurisdictions.

This shows, then, that law firms continue to face a real quandary because of conflicting organizational/managerial logics and professional sensibilities. An alternative strategy to that described above is the logic used by many firms for the management of training programmes (table 3). Here it is recognized that a combination of the different regulatory environments controlling training programmes for newly qualified lawyers (defined by disciplinary enforcement bodies such as the Law Society in England) and the different cultural approaches to associate mentoring taken by lawyers, something reinforced by the nature of university education (table 3), result in the need for locally-specific organizational approaches that cannot be replicated throughout the firm. Of course, this is the most extreme form of non-isomorphism and creates even less centralized 'control' structures than in hybrid approaches. A limited degree of sharing of best practice and an inability to standardize training is the likely outcome. In organizations so reliant on the knowledge of their workforce this would seem paradoxical. It is, however, necessary because of the peculiarities of professionals who demand the autonomy to work in ways they see (culturally) fit. 


\section{Conclusions}

This analysis of the impact of professionalism and its spatialities on the organization of PSFs ultimate returns us to our initial discussions of extant theory on the globalization and definition of PSFs. In terms of globalization, professional idiosyncrasies mean that ownership, location and internalization advantages are not necessarily as easy to exploit as is suggested by the eclectic paradigm. As our analysis suggests, lawyers, as professionals, treasure the occupational principles of independence and discretion. This legacy of autonomy is reflected in a series of practices in transnational law firms such as the reliance on committees and the consensual approach to decision-making, something that interferes with the 'managerial' priorities of integration, expediency and efficiency often associated with successful globalization strategies. Existing studies of global PSFs have somewhat under-theorised these impacts of the employed professionals on organizational strategies and hence the problematic nature of attempts to transplant concepts developed from studies of manufacturing organizations to the study of PSFs.

We have also shown here that, in addition, integrated organizational designs and coherent practices are also hindered by the existence of spatially diverse forms of professionalism and professional projects and the resultant variations in how professional work is defined, managed, evaluated and remunerated across national jurisdictions. This is what we refer to as the 'varieties of professionalism' and has a dramatic impact on the way in which the embedded relational networks used by PSFs are organized and managed (Dicken et al. 2001). It means that bridging the cultural gap 
between spatially heterogeneous professionals and their values through negotiations is essential (Ackroyd 2002). This all points to the importance of fully exploring the spatial peculiarities of professionalism; something that has been neglected in recent times and not incorporated into discussions of the organizational forms of globalizing PSFs.

Of course, out of necessity the remit of this paper is more to set a number of future research questions and highlight current empirical lacuna in relation to these topics, rather than provide substantive and definitive discussions. The example of accountancy firms shows why such a task is so important. As noted, these firms have a much greater geographical reach than law firms and have been negotiating the challenges of professionalism for many years. We drew on the work of Covaleski et al (1998) to highlight how these firms manage professionalism through attempts to socialize professionals into organizational logics. However, we know little about how the principles and values of professionalism vary compared with those described here for law and the complexity of the varieties of professionalism is not addressed in this work. The fact that accountancy firms remain national partnerships operating as jurisdictionally independent entities under an overarching corporate umbrella does, of course, mean that the challenges of the national varieties of professionalism will be different to law firms where global partnership agreements have to cater to the sensitivities of lawyers worldwide. Increasingly accountancy firms have suggested they may adopt the global partnership mode, although to date there are few signs of movement in this a direction, and the case study of law offered here might provides us with a conceptual lens through which we could approach the 
study of this issue. Providing a conceptual frame for such research is, then, one of the main aims of this paper.

This, then, brings us back to the start of the paper where we noted the importance of raising questions about how to define PSFs. It may be legitimate to question the broad use of the term PSF and attempt to redefine the concept based upon comparative studies of both 'traditional' professional industries (accountancy, architecture, law etc.) but also the socalled nouvelle professions (advertising, executive search and project management) with, of course, in the case of management consultancy and accountancy the two breeds coming together in one firm. It seems likely that we will find significant variations in the meaning and values of professionalism between these industries and, therefore, diverse management challenges. In such studies the distinction made between occupational professionalism (the principle of autonomy) and professional projects and their associated actors and legacies seem likely to be important. We suggest that theorising the identities, values and associated behaviours of professionals, in a range of organizational settings, should be based on understanding of these two dimensions, thus requiring in-depth studies of professionals and their values and how these, together with regulators, educational institutions and clients, negotiate historically and spatially contingent structures, configurations and practices. Here it might also be profitable to make links to debates on transnational governance regimes and changing institutional systems (Djelic and Sahlin-Andersson, 2006; Morgan and Quack 2005). The way each profession, as a coherent group of actors, is or is not becoming global through the standardization of 
procedures, ideals and norms and the mechanisms behind this (including the role of TNCs as drivers of change and national institutions as resisters or enablers of change) seems increasingly important. In this sense what we offer here is an initial attempt at reincorporating the professional into the study of PSFs through a selective case study of law that highlights some of the main issues in need of further consideration.

\section{Acknowledgements}

Thanks to Jon Beaverstock for comments on an earlier version of this paper. Versions of the paper were also presented at the 2006 Annual Conference of the Clifford Chance Centre for the Study of Professional Service Firms in Barcelona and the $18^{\text {th }}$ Annual SASE Meeting in Trier, Germany. Feedback received at these events helped focus the arguments made in the paper. The usual disclaimers apply.

\section{Endnotes}

${ }^{1}$ Megalaw is the term used to refer to large law firms where teams of associates, managed by partners, are used to effectively, efficiently and profitably (for the law firm) mange large transactions.

${ }^{2}$ Of course, creating such a dichotomy is misleading and in recent years in particular firms have begun to change the models they use, often away from what 
is traditionally associated with their home country. The distinction proposed holds true for all but three of the firms represented by interviewees. Of these outliers, one UK firm used a merit based approach and two US firms used a lockstep model. 


\section{References}

Abel, R.L. (1988) The legal profession in England and Wales. New York: Blackwell.

Ackroyd, S. (2002) The organization of business: applying organizational theory to contemporary change. Oxford: Oxford University Press.

Aharoni, Y.(1993) Coalitions and competition: the globalization of professional business services. Routledge: London

Alvesson, M. (2004) Knowledge work and knowledge intensive firms. Oxford: Oxford University Press.

Bagchi-Sen, S. and Sen, J. 1997. 'The Current State of Knowledge in International Investments in Producer Services' Environment and Planning A, Vol. 29, pp. 1153-1174.

Bartlett, C. and Ghoshal, S. (1998) Managing across borders: the transnational solution. London: Random House.

Baumann, J. R. (1999) Pioneering a global vision. The story of Baker \& McKenzie. Chicago: Harcourt Professional Education Group.

Beaverstock, J V. (2004) 'Managing across borders: knowledge management and expatriation in professional legal service firms'. Journal of Economic Geography, $4(2), 157-179$

Beaverstock, J V, Smith, R and Taylor, P J. (1999) 'The long arm of the law: London's law firms in a globalising world economy'. Environment and Planning A, $13,1857-1876$

Broadbent, J., Dietrich, M. and Roberts, J. (eds) (1997) The end of the professions? The restructuring of professional work. London and New York: Routledge.

Brock, D., M. Powell, and C.R. Hinings (eds.) (1999), Restructuring the professional organization: Accounting, healthcare, and law. London: Routledge. 
Burrage, M. and Torstendahl, R. (eds.) (1990) The professions in theory and history. London: Sage.

Burrage, M., K., Jaraush, and H., Siegrist (1990) 'An actor based framework for the study of professionalism' in Burrage, M. and Torstendahl, R. (eds.) The professions in theory and history. London: Routledge pp 203-226.

Cooper, D., C.R. Hinings, R, Greenwood, and J.L. Brown (1996), 'Sedimentation and transformation: The case of Canadian law firms'. Organization Studies, 17 (4), 623-647

Covaleski, M.A., Dirsmith, M.W., Heian, J.B. and Samuel, S (1998) 'The calculated and the avowed: Techniques of discipline and struggles over identity in Big Six public accounting firms' Administrative Science Quarterly, 43(2), 293-327., Daniels, P. W., Leyshon, A. and Thrift, N. (1988) 'Large accountancy firms in the UK: Operational adaptation and spatial development' The Service Industries Journal, 8, 317-346.

Daniels, P. W. (1993) Service industries in the world economy. Oxford: Blackwell.

Dicken, P. 2003. Global Shift. London: Sage

Dicken, P., Kelly, P. F., Olds, K. and Yeung, H. W.-C. (2001) 'Chains and network, territories and scales: towards a relational framework for analysing the global economy' Global Networks, 1, 89-112.

Djelic, M.-L. and K. Sahlin-Andersson (2006) Transnational Governance: Institutional Dynamics of Regulation. Cambridge: Cambridge University Press. Dunning, J. and Norman, G. (1987) 'Theory of multinational enterprise' Environment and Planning A, 15, 675-692.

Empson, L. and Chapman, C. (2006) 'Partnership versus corporation: implications of alternative governance for managerial authority and organizational priorities in professional service firms' Research in the Sociology of Organizations, 24, 145176. 
Enderwick, E. P. (Ed) (1989) Multinational service firms. London: Routledge.

Faulconbridge, J R. (2006) 'Stretching tacit knowledge beyond a local fix? Global spaces of learning in advertising professional service firms' Journal of Economic Geography, 6, 517-540

Faulconbridge, JR. (in press) 'Relational networks of knowledge production in transnational law firms' Geoforum

Flood, J. (1995). 'The cultures of globalization: professional restructuring for the international market', in Dezalay, Y. and D., Sugarman (eds) Professional competition and professional power. Lawyers, accountants and the social construction of markets, pp 139-169. London: Routledge

Flood, J. (1999) 'Professionals organizing professionals: comparing the logic of US and UK law practice', in Brock, D., M. Powell and C.R. Hinings (eds) Restructuring the professional organization: accounting, healthcare, and law, pp 154-182 London: Routledge.

Freidson, E. (1970) Professional dominance: the social structure of medical care. New York: Atherton Press.

Freidson, E. (1994) Professionalism reborn: theory, prophecy, and policy. Chicago: University of Chicago Press.

Freidson, E. (2001), Professionalism: The third logic. Cambridge: Polity.

Greenwood, R, Hinings, C and Brown, J S. (1990) 'P2-Form strategic management: corporate practices in professional partnerships' Academy of Management Journal, 33 (4), 725-755.

Gray, J. (1999) 'Restructuring law firms: reflexivity and emerging forms' in Brock, D., M. Powell and C.R. Hinings (eds) Restructuring the professional organization: accounting, healthcare, and law, pp 87-104 London: Routledge.

Hall, P. A. and Soskice, D. (2001) Varieties of capitalism. The institutional foundations of comparative advantage. Oxford: Oxford University Press. 
Hanlon, G. and J. Shapland (1997) 'Professional disintegration? The case of law' in Broadbent, J., Dietrich, M. and Roberts, J. (eds) The end of the professions? The restructuring of professional work, pp 104-122 London and New York: Routledge. Hinings, C.R., R. Greenwood and D. Cooper (1999) 'The dynamics of change in large accounting firms' in Brock, D., M. Powell and C.R. Hinings (eds) Restructuring the professional organization: accounting, healthcare, and law, $\mathrm{pp}$ 131-153 London: Routledge.

Johnson, T.J. (1972) Professions and power. London: Macmillan.

Jones, A. (2002) 'The global city misconceived: the myth of 'global management' in transnational service firms' Geoforum, 33, 335-350.

Larson, M. S. (1977), The rise of professionalism: A sociological analysis. Berkeley: University of California Press.

Lawyer, The (1999) 'Square Mile' The Lawyer, $8^{\text {th }}$ September 1999 Lawyer, The (2004) 'Lockstep revolution beckons' The Lawyer $8^{\text {th }}$ March 2004 Lawyer, The (2005) The Global 100. The Lawyer, London.

Lowendahl, B. (2005) Strategic management of professional service firms. Copenhagen: Copenhagen Business School Press.

MacDonald, K.M. (1995) The sociology of the professions. London; Thousand Oaks, Calif.: Sage.

Mintzberg, H. (1983) Structure in fives: designing effective organizations. Englewood Cliffs; London: Prentice-Hall.

Montagna, P.D. (1968) 'Professionalisation and bureaucraticisation in large professional organizations' The American Journal of Sociology, 74(2), 138-45

Morgan, G. (2001) 'Transnational communities and business systems' Global Networks, 1, 113-130. 
Morgan, G and Quack, S. (2005) 'Institutional legacies and firm dynamics: the growth and internationalization of UK and German law firms' Organization Studies, 26 (12), 1765-1785

Nelson, R. L. and Trubek, D. M. (1992) 'Introduction. New problems and new paradigms in studies of the legal profession', in B. L. Nelson, D. M. Trubek and R. L. Solomon (eds) Lawyers' ideals/lawyers' practices. Transformations in the American legal profession, London: Cornell University Press, 1-27.

New York Law Journal, The (2005) Clifford Chance partners approve reform of lockstep compensation system. New York Law Journal 19 ${ }^{\text {th }}$ December 2005.

Raelin, J. (1991) The clash of cultures. Managers managing professionals. Boston: Harvard Business School Press.

Sklair, L. (2001) The Transnational Capitalist Class, Oxford: Blackwell Taylor, M. and Asheim, B. (2001) 'The concept of the firm in economic geography' Economic Geography, 77, 315-328.

Trubeck, D., D. Dezalay, R. Buchanan and J. Davis (1994) 'Global restructuring and the law: the internationalization of legal fields and the creation of transnational arenas', Case Western Reserve Law Review, 44, 407-498.

Ward, K. (2005) 'Making 'flexible' Manchester: competition and change in the temporary staffing industry', Geoforum 36 223-240.

Whitley, R. (1998) 'Internationalization and varieties of capitalism: the limited effects of cross-national coordination of economic activities on the nature of business systems', Review of International Political Economy, 5, 445-481.

Wrigley, N., Coe, N. and Currah, A. (2005) 'Globalizing retail: conceptualizing the distribution-based transnational corporation (TNC)', Progress in Human Geography, 29, 437-457 


\begin{tabular}{|c|c|c|}
\hline Firm & Country of Origin & No. Offices (2006) \\
\hline Clifford Chance & England & 34 \\
\hline Linklaters & England & 31 \\
\hline $\begin{array}{l}\text { Skadden Arps Slate } \\
\text { Meagher \& Flom }\end{array}$ & USA & 23 \\
\hline $\begin{array}{c}\text { Freshfields Bruckhaus } \\
\text { Deringer }\end{array}$ & England & 28 \\
\hline Latham \& Watkins & USA & 22 \\
\hline Allen \& Overy & England & 26 \\
\hline Baker \& McKenzie & USA & 69 \\
\hline Jones Day & USA & 18 \\
\hline White \& Case & USA & 39 \\
\hline Weil Gotshal \& Manges & USA & 16 \\
\hline
\end{tabular}

Table 1 . Top 10 transnational law firms by number of offices. 
The creation of a corporate identity and Focussing of work around certain practice specialities that underlie the long-term reputation strategy of the firm

Avoidance of conflicts of interest that hinder Centralised control of client acceptance to ensure any new clients will not create the acceptance of strategic work significant 'off limits' issues (e.g. firms specialising in M\&A are unlikely to accept a case where a bank is sued as this will prevent them representing a client using this bank in the future)

Effective leverage of knowledge and Knowledge management initiatives, often at the practice group level, and the creation of capabilities within the firm expertise databases and forms of computerised knowledge management (e.g. case review reports; blogs)

Maintenance of profits margins All staff subject to formal review process which includes various targets and performance criteria

Table 2. Organizational challenges in global legal PSFs and 'managerial' responses.

Source: Lead author's fieldwork 


\begin{tabular}{|c|c|c|}
\hline Characteristic & US approach & English approach \\
\hline $\begin{array}{l}\text { Degree of specialisation of } \\
\text { firm }\end{array}$ & $\begin{array}{l}\text { High - focussed on a limited range of } \\
\text { transaction types }\end{array}$ & Moderate - more 'complete service' \\
\hline Co-ordination of activities & $\begin{array}{l}\text { High levels of partner review, usually } \\
\text { annually }\end{array}$ & $\begin{array}{l}\text { Moderate - 'light touch' coordination with more } \\
\text { informal reviews taking place bi-annually or at more } \\
\text { infrequent intervals }\end{array}$ \\
\hline Internal stratification & $\begin{array}{l}\text { High - partner/associate (senior/junior) } \\
\text { divisions marked }\end{array}$ & $\begin{array}{l}\text { Moderate - partners and associates interact in a less } \\
\text { formalised fashion }\end{array}$ \\
\hline $\begin{array}{l}\text { Managerial 'power' held by } \\
\text { partners }\end{array}$ & $\begin{array}{l}\text { Greater presence of an elite strata (partners } \\
\text { with power) willing to enforce decisions }\end{array}$ & $\begin{array}{l}\text { Management by consensus with even the most senior } \\
\text { partners holding less sway and tending to be less } \\
\text { authoritarian }\end{array}$ \\
\hline Performance management & $\begin{array}{l}\text { Ruthless 'up or out' mentality where } \\
\text { associates performance closely monitored. }\end{array}$ & $\begin{array}{l}\text { 'Up or out system' used but performance standards not } \\
\text { as harsh. }\end{array}$ \\
\hline
\end{tabular}




\begin{tabular}{|c|c|c|}
\hline \multirow{4}{*}{$\begin{array}{l}\text { Training and staff } \\
\text { development }\end{array}$} & Responsibility taken by a restricted circle of & Collegial responsibility taken on by all senior partners. \\
\hline & partners with many unwilling to spend time & Informal supervision through one to one mentorship \\
\hline & on training activities. Little or no use of & system and office sharing. Use of Professional Support \\
\hline & Professional Support Lawyers & Lawyers to provide training. \\
\hline Remuneration Model & 'Eat-what-you-kill' & 'Lock-step' \\
\hline & $\begin{array}{l}\text { Remuneration is tied to individual } \\
\text { contributions }\end{array}$ & Remuneration is tied to seniority \\
\hline Workload & $\begin{array}{l}\text { Formal billable hours targets for various } \\
\text { categories of employees } \\
\text { Targets in excess of } 2000 \text { hours per annum }\end{array}$ & $\begin{array}{l}\text { Varies across firms but less reliance on formal targets. } \\
\text { Targets where they exist are not as demanding as in } \\
\text { the US }\end{array}$ \\
\hline
\end{tabular}

Table 3. The characteristics of US and English law firms and lawyers.

Source: Based on Flood (1989), Ackroyd (1996), Wilkins (2001) and lead author's fieldwork. 


\section{Organizational Exemplary management issues \\ Approach used}

\section{challenge}

Strategic Conflicts of interest

Practice group structuring
Centrally managed conflict of interest checks and procedures that all lawyers have to follow in a uniform fashion.

A number of practices areas are defined as being 'firm-wide' and all offices have to specialise in these areas. The local organization of the exact types of work done within those groups and the types of speciality lawyers have are determined at the local level depending on local norms (e.g. corporate litigation is always the biggest practice in the USA). 
Financial

Remuneration models

Financial performance targets
Negotiated 'hybrid' forms used throughout the firm. These have to be acceptable in the two dominant remuneration cultures in global law firms - eat what you kill and lockstep and reflect 'local' norms and expectations in each of the jurisdictions operated within.

Minimum firm-wide billable hours targets exist for partners and associates throughout the firm but each office monitors and enforces (with varying degrees of stringency) these as they see fit (e.g. in the USA billable hours are expected to be much higher than the firm average).

Operational Associate training and development Each office designs its own associate training and development programme. programmes

Table 3. Management strategies in global PSFs and their mediation by professional practices and identities.

Source: Lead author's fieldwork. 